\title{
Ausblick - wie gestalten wir die Zukunft?
}

Helmut Müller hat die neuesten Marktforschungsstudien mittlerweile intensiv studiert und das Strategische Marketing sowie den Vorstand zu einem Gesprächstermin gebeten. Auf Basis der Marktforschungsstudien müssen nun Lösungen gefunden werden, um weiterhin erfolgreich am Markt bestehen zu können und existenzsichernde Wettbewerbsvorteile zu erzielen.

Die Marktforschungsstudien entsprachen den Kritiken der Jugendlichen und der Absatzkraft der verschiedenen Produkte: Der Konsument möchte sich gesund ernähren, möchte aber gleichzeitig den Genuss nicht missen. „Genuss ohne Reue“, resümiert Helmut Müller. Der Vorstand pflichtet ihm bei, merkt jedoch auch an, dass es im Bereich Laktose- und Gluten-freier Ernährung oder im Bereich Nachhaltigkeit ggf. auch Marktchancen für Nibbles geben könnte.

Es gab viele erfolgsversprechende Ideen. Man durfte jedoch nicht außer Acht lassen, dass ein neues Produkt auch massenmarkttauglich sein musste. In einen Nischenmarkt einzudrängen, wäre zu riskant, und auch in Bezug auf die Produktionskosten nicht haltbar.

Nächste Woche würde das Strategische Management zusammen mit Helmut Müller tagen und Konzepte für neue Produktideen erarbeiten. Die Zeit drängt, der Markt schläft nicht ... 